\title{
Fruit and vegetable consumption among adults in Saudi Arabia, 2013
}

\author{
This article was published in the following Dove Press journal: \\ Nutrition and Dietary Supplements \\ 20 February 2015 \\ Number of times this article has been viewed
}

\author{
Charbel El Bcheraoui' \\ Mohammed Basulaiman ${ }^{2}$ \\ Mohammad A AIMazroa ${ }^{2}$ \\ Marwa Tuffaha' \\ Farah Daoud' \\ Shelley Wilson' \\ Mohammad Y Al Saeedi ${ }^{2}$ \\ Faisal M Alanazi \\ Mohamed E Ibrahim² \\ Elawad M Ahmed ${ }^{2}$ \\ Syed A Hussain ${ }^{2}$ \\ Riad M Salloum ${ }^{2}$ \\ Omer Abid ${ }^{2}$ \\ Mishal F Al-Dossary ${ }^{2}$ \\ Ziad A Memish² \\ Abdullah A Al Rabeeah ${ }^{2}$ \\ Ali $\mathrm{H}_{\text {Mokdad' }}$ \\ 'Institute for Health Metrics and \\ Evaluation, University of Washington, \\ Seattle, WA, USA; ${ }^{2}$ Ministry of Health \\ of the Kingdom of Saudi Arabia, \\ Riyadh, Saudi Arabia
}

Correspondence: Ali H Mokdad Institute for Health Metrics and Evaluation, University of Washington, 230I, 5th Avenue, Suite 600, Seattle, WA 98121 , USA

$\mathrm{Tel}+\mathrm{I} 2068972849$

Fax + I 2068972899

Emailmokdaa@uw.edu
Background: Dietary risks were the leading risk factors for death worldwide in 2010. However, current national estimates on fruit and vegetable consumption in the Kingdom of Saudi Arabia (KSA) are nonexistent. We conducted a large household survey to inform the Saudi Ministry of Health $(\mathrm{MOH})$ on a major modifiable risk factor: daily consumption of fruits and vegetables.

Methods: The Saudi Health Interview Survey is a national multistage survey of individuals aged 15 years or older. It includes questions on sociodemographic characteristics, tobacco consumption, diet, physical activity, health care utilization, different health-related behaviors, and self-reported chronic conditions. We used a backward elimination multivariate logistic regression model to measure association between the Centers for Disease Control and Prevention (CDC)-recommended daily consumption of fruits and vegetables and different factors.

Results: Between April and June 2013, a total of 10,735 participants completed the survey. Overall, 2.6\% of Saudis aged 15 years or older met the CDC guidelines for daily consumption of fruits and vegetables. The likelihood of meeting the CDC guidelines increased with age; among women; among persons who graduated from elementary or high school or had a higher education; among residents of Makkah, Al Sharqia, Ha'il, or Jizan; among those who consumed at least two servings of meat or chicken per day; among those who visited a health care facility for a routine medical exam within the last 3 years; and among those who have been diagnosed with hypertension.

Conclusion: We have showed that KSA is in dire need of improving the diet of its population. Our findings call for urgent research to understand the reasons for low fruit and vegetable consumption, focusing on price or preference in order to develop and implement culturally and country-relevant solutions to increase the consumption of fruits and vegetables.

Keywords: Kingdom of Saudi Arabia, fruits, vegetables, dietary risks, diet

\section{Introduction}

Dietary risks were the leading risk for death, years of life lost, and disability-adjusted life years worldwide in $2010 .{ }^{1}$ The sociocultural evolution of the last century led to increased access to food, specifically in the Gulf region where oil revenues increased wealth. ${ }^{2}$ People of the Gulf region traditionally did not consume much fruits and vegetables, except for dates, due to the harsh desert environment. The main source of energy was meat, dairy products, and carbohydrates. As wealth and imports made all kinds of fruits and vegetables available, we would expect a change in diet from the traditional low levels of consumption to more consumption of fruits and vegetables.

Several recommendations by the World Health Organization, the US Department of Agriculture, and the Department of Health and Human Services exist to improve 
diet and increase the intake of fruits and vegetables., ${ }^{3,4}$ The 5 a day program started in $1990^{5}$ and has evolved based on scientific evidence. ${ }^{4}$ Specifically, an increased intake of fruits and vegetables has been associated with decreased weight and risk of cardiovascular disease morbidity and mortality. ${ }^{6-13}$ Currently, the US Centers for Disease Control and Prevention (CDC) recommend consuming a certain number of servings of fruits and vegetables (recommendations vary based on sex and age). ${ }^{14}$

The Kingdom of Saudi Arabia (KSA) has witnessed a demographic shift over the last 20 years; this was accompanied by major behavioral changes such as an increase in caloric, fat, and carbohydrate intake. ${ }^{15}$ The Saudi Ministry of Health $(\mathrm{MOH})$ issued its dietary guidelines for Saudis as part of its fight against obesity in 2013, as $28.7 \%$ of Saudis aged 15 years or older are obese. ${ }^{16,17}$

Current national data on fruit and vegetable consumption in KSA are nonexistent, and the most recent estimates date from 2005. ${ }^{18}$ To assess the current daily consumption of fruits and vegetables in $\mathrm{KSA}$, and provide the $\mathrm{MOH}$ with an evidence base on the predictors of this major modifiable risk factor, we conducted a large household survey.

\section{Subjects and methods}

The Saudi Health Interview Survey is a national multistage survey of individuals aged 15 years or older. Households of Saudi citizens were randomly selected from a national sampling frame maintained and updated by the Census Bureau. The $\mathrm{MOH}$ divides KSA into 13 health regions, each with its own health department. We divided each region into subregions and blocks used by the KSA Department of Statistics. All regions were included, and a probability proportional to size was used to randomly select subregions and blocks. Households were randomly selected from each block. We collected a roster of household members and randomly selected an adult aged 15 or older to be surveyed. If the randomly selected adult was not present, our surveyors made an appointment to return, and a total of three visits were made before the household was considered as a nonresponse.

The survey included questions on sociodemographic characteristics, tobacco consumption, diet, physical activity, health care utilization, different health-related behaviors, and self-reported chronic conditions (hypertension, diabetes, and hypercholesterolemia).

Consumption of fruits and vegetables was measured using a frequency questionnaire. Daily fruits consumption was assessed by asking the following two questions: "In a typical week, on how many days do you eat fruit? Please include fresh, frozen, or canned fruit, for example, figs, grapes, oranges, bananas, or apples. Do not include juices, blended fruits, or dried fruits" and "How many servings of fruit do you eat on one of those days?" Daily fruit juices consumption was assessed by asking the following two questions: "In a typical week, on how many days do you drink 100\% fruit juices, including blended fruits? Do not include nectars" and "How many servings of $100 \%$ fruit juices do you drink on one of those days?" Daily vegetables consumption was assessed by asking the following two questions: "In a typical week, on how many days do you eat vegetables? Please include raw, cooked, canned, or frozen vegetables. Please do not include rice, potatoes, or cooked dried beans such as kidney beans, pinto beans, or lentils" and "How many servings of vegetables do you eat on one of those days?" We then computed the numbers of fruits and vegetables consumed per day as the sum of the average daily consumption of fruits, fruit juices, and vegetables.

Our survey included questions on sodas, red meat, processed meat, chicken, dark-meat fish, other types of fish, shrimp, processed food, milk, laban (yogurt), ayran (yogurt beverage mixed with salt), labneh (traditional spreadable cheese), cheese, nuts, and eggs. These were assessed using a methodology similar to the one of fruit, juice, and vegetable consumption. We assessed the type of bread the respondents usually consume by asking: "What type of bread do you usually eat?" Respondents could choose between white, brown, and Saudi traditional bread.

Although our survey did not include questions on carbohydrates such as pasta and rice, we calculated the caloric intake from all available food items using the National Nutrient Database for Standard Reference from the US Department of Agriculture. This is an underestimate of the total caloric intake in the Kingdom, as rice is a staple there, but we felt the estimate of total caloric intake was still important to include in our analysis.

Respondents were considered to be current smokers if they reported currently smoking. We used the International Physical Activity Questionnaire ${ }^{19}$ to classify respondents into four groups of physical activity: 1) vigorous physical activity, 2) moderate physical activity, 3) insufficient physical activity, and 4) none.

To assess diagnosed blood pressure, diabetes, and hypercholesterolemia status, respondents were asked three separate questions: "Have you ever been told by a doctor, nurse, or other health professional that you had: 1) hypertension, otherwise known as high blood pressure; 2) diabetes mellitus, otherwise known as diabetes, sugar diabetes, high 
blood glucose, or high blood sugar; 3) hypercholesterolemia, otherwise known as high or abnormal blood cholesterol?' Women diagnosed with diabetes or hypertension during pregnancy were not counted as having these conditions.

To assess time since last routine medical checkup, respondents were asked, "In which year did you last visit a doctor or other health professional for a routine checkup? A routine checkup is a general physical exam, not an exam for a specific injury, illness, or condition."

We compared the distribution of respondents who met the Saudi and the CDC guidelines for daily consumption of fruits and vegetables to those who did not by sociodemographic, behavioral, and health characteristics. The Saudi guidelines recommend consuming at least two servings of fruits and three servings of vegetables per day. The CDC guidelines recommend consuming at least 1) two servings of fruits and three servings of vegetables for men aged 15-18 years or 21-60 years; 2) two servings of fruits and three-and-a-half servings of vegetables for men aged 19-20 years; 3) two servings of fruits and two-and-a-half servings of vegetables for men older than 20 years and women aged 19-25 years; 4) one-and-a-half servings of fruits and two-and-a-half servings of vegetables for women aged 15-18 years or 26-50 years; and 5) one-and-a-half servings of fruits and two servings of vegetables for women older than 50 years.

We used a backward elimination multivariate logistic regression model to measure association between adequate consumption of fruits and vegetables per day, based on the CDC recommendations, and associated factors. All factors were included in the model. Then variables were eliminated based on a Wald $\chi^{2}$ test for analysis of effect. Variables were removed one by one based on the significance level of their effect on the model, starting with the variable with the highest $P$-value $>0.5$, until all variables retained had a $P$-value $\leq 0.5$ in the analysis of effect. The logistic regression excluded cases with missing data. Out of the 10,735 completed interviews, the regression analysis excluded 266 observations missing self-reported hypercholesterolemia status, 115 missing self-reported diabetes status, 212 missing fruit and vegetable consumption, 173 missing meat and chicken consumption, 29 missing smoking status, 33 missing marital status, and 20 missing educational level. In total, 9,993 observations were used in our regression analyses. Data were weighted to account for the probability of selection, and age and sex post-stratification, based on census data for age and sex distribution of the Saudi population. We used SAS 9.3 for the analyses and to account for the complex sampling design.

\section{Ethics}

The Saudi MOH and its institutional review board (IRB) have approved the study protocol. The University of Washington IRB has deemed the study as IRB exempt, since the Institute for Health Metrics and Evaluation received de-identified data for this analysis. All respondents consented and agreed to participate in the study. We used verbal consent that was captured by our computer program, since it is commonly used and accepted in KSA. Two verbal consents were obtained: one for the household roster (obtained from the head of the household or the most knowledgeable person in the house) and another obtained from the randomly selected respondent. The KSA MOH and the University of Washington IRB approved the verbal consents that were obtained in this study.

\section{Results}

Between April and June 2013, a total of 12,000 households were contacted, and a total of 10,735 participants completed the survey (response rate of $89.4 \%$ ).

The majority of our participants consumed less than two servings of fruits and vegetables per day (Table 1). Overall, 2.6\% of Saudis aged 15 years or older met both the Saudi and the CDC guidelines for daily consumption of fruits and vegetables. The largest variations in consumption were observed between regions and number of daily servings consumed of meat and chicken. While $0.2 \%$ of Al Jawf residents met the $\mathrm{CDC}$ guidelines for daily consumption of fruits and vegetables, 9.6\% of 'Asir residents did so. Also, the proportion of people meeting the guidelines increased from $0.9 \%$ among those who consumed between $0-0.9$ and 1.0-1.9 servings of meat and chicken per day to $3.3 \%$ and $8.4 \%$ among those who consumed 2.0-2.9 and 3.0+ servings of meat and chicken per day, respectively (Table 1).

In the multivariate analysis, several factors were associated with the likelihood of meeting the CDC guidelines for daily consumption of fruits and vegetables. This likelihood increased with age and among women, persons who graduated from elementary or high school or had a higher education, and residents of Makkah, Al Sharqia, Ha'il, and Jizan. It also increased with increased daily caloric intake, and among individuals who consumed at least two servings of meat or chicken per day, those who last visited a health care facility for a routine medical exam less than 3 years ago, and those who had been diagnosed with hypertension (Table 2).

\section{Discussion}

Our manuscript is the first to report on national consumption of fruits and vegetables in the KSA. Our results showed 


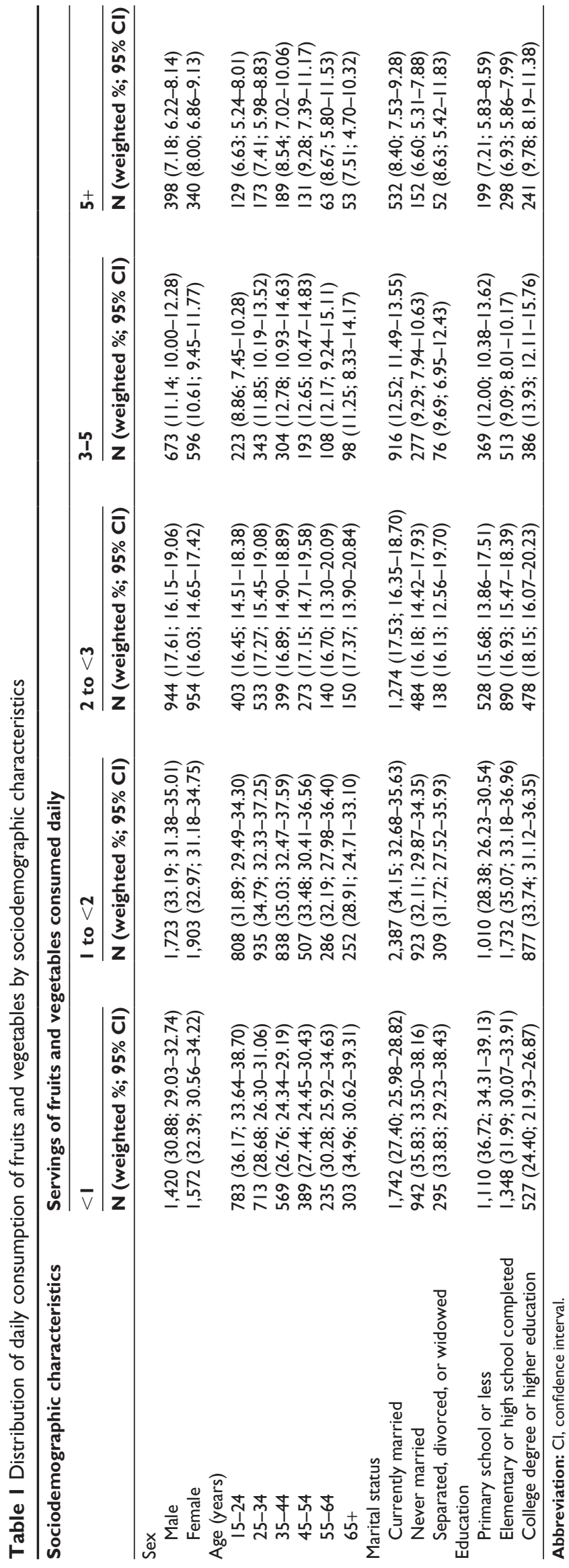

very low consumption of fruits and vegetables in the country among all segments of the population. This is an alarming finding and calls for immediate programs to encourage intake of fruits and vegetables to prevent diseases and reduce burden on families and the health system.

Our findings showed little or no improvement from a previous STEPS survey and after efforts of the $\mathrm{MOH}$ to increase the consumption of fruits and vegetables. In 2005, $5.5 \%$ of Saudis aged 15-64 years reported consuming at least five servings of fruits and vegetables per day. ${ }^{18}$ This increased to only $7.3 \%$ in our survey for the same age group. These findings call for a review of current programs, barriers, and determinants of a healthy diet, especially because current guidelines for fruit and vegetable consumption are only met by $2.6 \%$ of Saudis.

Despite this low intake of fruits and vegetables overall, it is noteworthy that this consumption increased with the educational level. Emphasizing the importance of a healthy diet rich with fruits and vegetables at schools is one way to increase such consumption.

Our data showed regional variation in fruit and vegetable consumption in KSA. However, none of the regions had high levels of intake, with 'Asir, where consumption is the highest, having only $9.6 \%$ of residents meeting the current guidelines for daily consumption of fruits and vegetables. While our data cannot provide an explanation on this regional variation, it would be relevant for future studies to investigate the factors behind the higher consumption of fruits and vegetables in some regions for policy formulation.

Our findings could be explained by several factors. Due to the climate, KSA traditionally had no major production of fruits and vegetables. Hence, Saudis did not consume many fruits and vegetables, except for dates that are produced in abundance. However, the recent wealth from oil revenues allowed for tremendous development of the agricultural sector in the region. ${ }^{2}$ Recent advances in agriculture, especially in areas bordering Yemen and Oman where there is enough rainfall to sustain agriculture, allowed the production of 4.7 million tons of fruits and vegetables in 2005, making the country $65 \%$ and $85 \%$ self-sufficient for fruits and vegetables, respectively, based on consumption patterns. ${ }^{2}$ Dates and tomatoes were the top fruits and vegetables produced. However, given our findings on the low consumption of fruits and vegetables in KSA, this production would be less than the reported percentages if Saudis were to meet the guidelines for fruit and vegetable consumption. There would also be a need for a higher production and import of fruits and vegetables. To address the current unmet needs, KSA imports 
Table 2 Distribution of different levels of daily fruit and vegetable consumption, and association between daily consumption of fruits and vegetables based on the CDC dietary guidelines and sociodemographic, behavioral, and health characteristics of Saudis aged I5 years or older in Kingdom of Saudi Arabia in 2013

\begin{tabular}{|c|c|c|c|c|c|}
\hline \multirow{2}{*}{$\begin{array}{l}\text { Sociodemographic, } \\
\text { behavioral, and health } \\
\text { characteristics }\end{array}$} & \multicolumn{2}{|c|}{$\begin{array}{l}\text { Meeting the Saudi } \\
\text { dietary guidelines }\end{array}$} & \multicolumn{2}{|c|}{$\begin{array}{l}\text { Meeting the CDC } \\
\text { dietary guidelines }\end{array}$} & \multirow{2}{*}{$\begin{array}{l}\text { Backward elimination } \\
\text { multivariate logistic } \\
\text { regression for } \\
\text { meeting the CDC } \\
\text { dietary guidelines } \\
\text { AOR }(95 \% \mathrm{CI})\end{array}$} \\
\hline & $\mathbf{N}$ & $\begin{array}{l}\text { Weighted \% } \\
(95 \% \mathrm{Cl})\end{array}$ & $\mathbf{N}$ & $\begin{array}{l}\text { Weighted \% } \\
(95 \% \mathrm{Cl})\end{array}$ & \\
\hline \multicolumn{6}{|l|}{ Sex } \\
\hline Male & 153 & $2.47(1.97-2.97)$ & 123 & $1.99(1.53-2.44)$ & Ref \\
\hline Female & 127 & $2.71(2.08-3.34)$ & 161 & $3.15(2.50-3.8 I)$ & $2.48(1.6 I-3.8 I)$ \\
\hline Age (years) & & & & & $1.43(1.18-1.74)$ \\
\hline $15-24$ & 33 & $1.29(0.76-1.83)$ & 29 & $1.20(0.67-1.72)$ & \\
\hline $25-34$ & 62 & $2.35(1.57-3.14)$ & 65 & $2.43(1.64-3.21)$ & \\
\hline $35-44$ & 74 & $3.66(2.58-4.75)$ & 72 & $3.58(2.51-4.65)$ & \\
\hline $45-54$ & 63 & $4.60(3.20-5.99)$ & 63 & $4.40(3.05-5.75)$ & \\
\hline $55-64$ & 29 & $4.53(2.27-6.79)$ & 32 & $4.77(2.46-7.08)$ & \\
\hline $65+$ & 19 & $3.52(1.45-5.59)$ & 23 & $3.97(1.84-6.11)$ & \\
\hline Marital status & & & & & Ref \\
\hline Currently married & 217 & $3.66(3.03-4.29)$ & 216 & $3.60(2.97-4.22)$ & $0.67(0.34-1.29)$ \\
\hline Never married & 45 & $1.35(0.85-1.86)$ & $4 \mid$ & $1.27(0.77-1.76)$ & $1.12(0.52-2.40)$ \\
\hline Separated, divorced, or widowed & 17 & $3.32(1.29-5.36)$ & 26 & $4.29(2.13-6.44)$ & \\
\hline Education & & & & & Ref \\
\hline Primary school or less & 62 & $2.13(1.42-2.85)$ & 76 & $2.52(1.76-3.28)$ & $2.25(1.27-3.98)$ \\
\hline Elementary or high school completed & 116 & $2.26(1.72-2.80)$ & 108 & $2.05(1.53-2.57)$ & $3.38(1.77-6.48)$ \\
\hline College degree or higher education & 102 & $4.02(3.01-5.04)$ & 100 & $3.93(2.93-4.94)$ & \\
\hline \multicolumn{6}{|l|}{ Region } \\
\hline Riyadh & 13 & $0.58(0.22-0.94)$ & 14 & $0.60(0.22-0.98)$ & Ref \\
\hline Makkah & 30 & $1.60(0.93-2.27)$ & 32 & $1.52(0.90-2.15)$ & $2.59(1.12-5.99)$ \\
\hline Al Madinah & 4 & $0.69(0.00-1.57)$ & 3 & $0.55(0.00-1.40)$ & $1.00(0.11-8.75)$ \\
\hline Al Qasim & 6 & $0.95(0.11-1.80)$ & 6 & $0.95(0.11-1.80)$ & $2.10(0.68-6.46)$ \\
\hline Al Sharqia & 57 & $6.75(4.86-8.64)$ & 56 & $6.63(4.76-8.5 I)$ & $6.38(2.9|-| 4.00)$ \\
\hline 'Asir & 97 & $9.59(7.52-11.67)$ & 98 & $9.56(7.50-11.63)$ & $10.56(5.03-22.19)$ \\
\hline Tabuk & 7 & $1.09(0.08-2.09)$ & 8 & $0.87(0.19-1.55)$ & $2.30(0.74-7.17)$ \\
\hline Ha’il & 19 & $2.46(1.18-3.73)$ & 18 & $2.53(1.21-3.85)$ & $5.17(2.16-12.38)$ \\
\hline Al Hudud ash Shamaliyah & 8 & $1.40(0.36-2.43)$ & 5 & $0.75(0.05-1.44)$ & $1.17(0.22-6.22)$ \\
\hline Jizan & 16 & $1.58(0.75-2.40)$ & 18 & $1.74(0.88-2.59)$ & $3.98(1.54-10.29)$ \\
\hline Najran & 14 & $1.26(0.54-1.98)$ & 14 & $\mathrm{I} .48(0.59-2.36)$ & $2.18(0.86-5.50)$ \\
\hline Al Bahah & 8 & $1.34(0.23-2.45)$ & 10 & $1.89(0.54-3.24)$ & $1.79(0.56-5.75)$ \\
\hline Al Jawf & I & $0.07(0.00-0.19)$ & 2 & $0.21(0.00-0.52)$ & $0.14(0.01-1.42)$ \\
\hline \multicolumn{6}{|l|}{ Smoking status } \\
\hline Never & 233 & $2.67(2.22-3.12)$ & 250 & $2.76(2.3 I-3.2 I)$ & \\
\hline Ex-smoker & 7 & $1.57(0.00-3.37)$ & 4 & $1.12(0.00-2.83)$ & \\
\hline Current smoker & 40 & $2.39(1.49-3.29)$ & 30 & $1.71(0.97-2.44)$ & \\
\hline \multicolumn{6}{|c|}{ Daily consumption of red meat and chicken (servings) } \\
\hline $0-0.9$ & 31 & $0.99(0.54-1.44)$ & 32 & $0.86(0.46-1.26)$ & Ref \\
\hline $1.0-1.9$ & 42 & $0.87(0.53-1.21)$ & 42 & $0.86(0.5 \mathrm{I}-\mathrm{I} .20)$ & $1.08(0.58-2.03)$ \\
\hline $2.0-2.9$ & 60 & $3.54(2.42-4.65)$ & 63 & $3.34(2.32-4.36)$ & $2.84(1.55-5.20)$ \\
\hline $3.0+$ & 143 & $8.17(6.41-9.93)$ & $|4|$ & $8.36(6.57-10.16)$ & $2.81(1.34-5.87)$ \\
\hline \multicolumn{6}{|l|}{ Levels of physical activity } \\
\hline None & 87 & $2.40(1.72-3.08)$ & 96 & $2.4 \mid(1.75-3.08)$ & \\
\hline Low & 79 & $2.91(2.08-3.74)$ & 83 & $2.99(2.16-3.83)$ & \\
\hline Moderate & 41 & $2.96(1.69-4.22)$ & 41 & $2.85(1.63-4.08)$ & \\
\hline Vigorous & 73 & $2.35(1.65-3.04)$ & 64 & $2.19(1.50-2.89)$ & \\
\hline \multicolumn{6}{|l|}{ Time since last routine medical exam } \\
\hline Within the last year & 109 & $6.60(5.11-8.10)$ & 107 & $6.18(4.75-7.60)$ & $1.86(1.17-2.96)$ \\
\hline I-3 years ago & 36 & $3.76(2.29-5.24)$ & 38 & $4.32(2.65-5.98)$ & $1.90(1.09-3.33)$ \\
\hline $4+$ years ago & 134 & $1.69(1.29-2.10)$ & 139 & $1.69(1.29-2.09)$ & Ref \\
\hline
\end{tabular}


Table 2 (Continued)

\begin{tabular}{|c|c|c|c|c|c|}
\hline \multirow{2}{*}{$\begin{array}{l}\text { Sociodemographic, } \\
\text { behavioral, and health } \\
\text { characteristics }\end{array}$} & \multicolumn{2}{|c|}{$\begin{array}{l}\text { Meeting the Saudi } \\
\text { dietary guidelines }\end{array}$} & \multicolumn{2}{|c|}{$\begin{array}{l}\text { Meeting the CDC } \\
\text { dietary guidelines }\end{array}$} & \multirow{2}{*}{$\begin{array}{l}\text { Backward elimination } \\
\text { multivariate logistic } \\
\text { regression for } \\
\text { meeting the CDC } \\
\text { dietary guidelines } \\
\text { AOR }(95 \% \mathrm{CI})\end{array}$} \\
\hline & $\mathbf{N}$ & $\begin{array}{l}\text { Weighted \% } \\
(95 \% \mathrm{CI})\end{array}$ & $\mathbf{N}$ & $\begin{array}{l}\text { Weighted \% } \\
(95 \% \mathrm{Cl})\end{array}$ & \\
\hline Daily caloric intake & $\begin{array}{l}\text { Mean =4,389.42; } \\
S E=187.37\end{array}$ & & $\begin{array}{l}\text { Mean =4,423. } 16 ; \\
S E=187.29\end{array}$ & & I.06 (I.04-I.08) \\
\hline History of diagnosis of hypertension & & & & & Ref \\
\hline No & 235 & $2.28(1.89-2.66)$ & 235 & $2.23(1.85-2.6 I)$ & $2.37(1.46-3.85)$ \\
\hline Yes & 44 & $6.88(4.29-9.48)$ & 47 & $7.07(4.50-9.65)$ & \\
\hline History of diagnosis of diabetes & & & & & Ref \\
\hline No & 229 & $2.35(1.95-2.75)$ & 231 & $2.32(1.93-2.72)$ & $\mathrm{I} .37(0.8 \mathrm{I}-2.34)$ \\
\hline Yes & 50 & $5.45(3.47-7.44)$ & 51 & $5.38(3.4 I-7.35)$ & \\
\hline \multicolumn{6}{|c|}{ History of diagnosis of hypercholesterolemia } \\
\hline No & 242 & $2.35(1.95-2.74)$ & 245 & $2.37(1.98-2.77)$ & \\
\hline Yes & 36 & $7.45(4.52-10.39)$ & 37 & $6.62(3.91-9.32)$ & \\
\hline
\end{tabular}

Notes: Significant AOR are presented in a bolded font. AOR are calculated per 10-year and 100-calorie increases for age and daily caloric intake, respectively. Smoking status, levels of physical activity, and history of diagnosis with hypercholesterolemia were included in the logistic regression but dropped out based on their effect on the model. Abbreviations: CDC, Centers for Disease Control and Prevention; $\mathrm{Cl}$, confidence interval; AOR, adjusted odds ratios; Ref, reference; SE, standard error.

$\$ 1.1$ billion USD of fruits and vegetables. ${ }^{20}$ In $2013-2014$, the Kingdom imported the equivalent of \$2.05 billion USD of agriculturally produced food from India alone. ${ }^{21}$

The prices of fruits and vegetables in the Kingdom fluctuate greatly and increase around major holidays, especially in the holy month of Ramadan, when demand increases by up to $15 \% .{ }^{20}$ Fruits and vegetables are relatively expensive, which prevents large segments of the population from buying them on a regular basis. The average monthly income in the Kingdom is 7,611 Saudi Riyal, about \$2,030 USD. ${ }^{22}$ Housing in KSA is a major cost and consumes about $18.4 \%$ of the general cost of living index. ${ }^{22}$ The monthly minimum amount of money recommended for food per person is about $\$ 163$ per month, ${ }^{23}$ or $\$ 864$ per household, since our survey showed an average of 5.3 persons per household.

In the Kingdom, imported foods are subject to a $5 \%$ import duty. ${ }^{24}$ Grain production was heavily subsidized in an attempt to be self-sufficient, ${ }^{2}$ and gasoline is heavily subsidized and sold as low as \$0.12 USD per liter. ${ }^{25}$ However, fruits and vegetables are neither exempt from import taxes nor subsidized. The findings of our study call for reviewing the subsidies in KSA. It is important to extend subsidies to fruit and vegetable production, similar to policies in the US for certain products. ${ }^{26}$ Furthermore, it may be time to consider supporting fruit and vegetable importers, while creating policies to protect the local producers. It is important to remember that if Saudis were to increase their consumption of fruits and vegetables to meet the $\mathrm{CDC}$ or $\mathrm{MOH}$ guidelines, the demand and therefore the prices would increase. Government statistics show that currently $65 \%$ and $85 \%$ of fruits and vegetables consumed are produced in KSA. To prevent an increase in price, an increase in local production, or a government support of imports, is needed. Hence, a major review of the agricultural plans and subsidies is crucial.

Our study has some limitations. First, our data are cross-sectional, and we cannot assess causality. Second, variables included in this analysis are self-reported and subject to recall bias. Third, individuals may have overestimated their consumption of fruits and vegetables as it is a desirable behavior, and we may have overestimated the true consumption in KSA. Finally, our dietary questionnaire excludes questions on carbohydrates in a country where rice consumption is common and therefore does not allow us to compute a full caloric intake. However, our study used standardized data collection methods and protocols. Moreover, we had a large sample size, a high response rate, and included all regions of KSA, and so our findings are nationally representative.

Our study calls for qualitative work to understand why Saudis do not consume fruits and vegetables, and whether it is a taste or preference issue due to the nomadic and desert history of the country or an issue of pricing. Each of these issues has its own solution. We recommend group discussions to get a clear sense of what is driving this behavior. The $\mathrm{MOH}$ should work with community elders and leaders and with women's groups to understand the barriers and develop targeted programs to improve fruit and vegetable consumption. 
The Arab and Saudi media has many cooking shows with specialized TV channels. ${ }^{27}$ The $\mathrm{MOH}$ should use such venues to introduce recipes for vegetarian cooking. The Kingdom was once part of the spice route and buzzed with caravans bringing this valuable merchandise from India to Damascus. ${ }^{28}$ These spices could be used to influence the Arab cuisine by adding flavor to vegetarian dishes and making them more appealing.

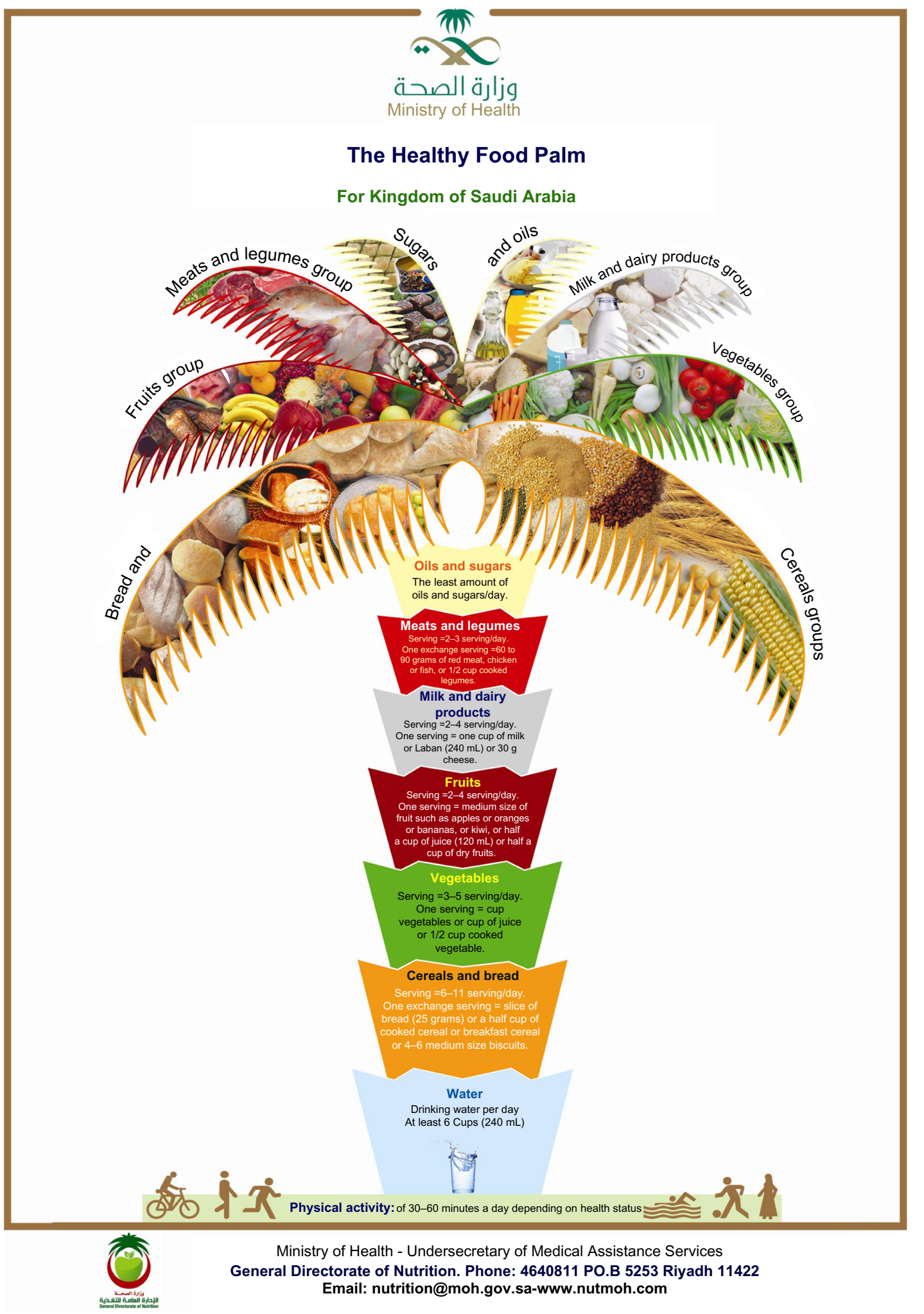

Figure I The Healthy Food Palm, Saudi Ministry of Health, 2012.

Note: Copyright @ 2012 . Figure reproduced courtesy of the Ministry of Health, Kingdom of Saudi Arabia; from Dietary Guidelines for Saudis. Riyadh: The Healthy Food Palm; $2012 .{ }^{32}$ 
$\mathrm{KSA}$ is a country deep in roots and culture, and solutions have to come from Saudis themselves. KSA is in need of a group or a person to champion the healthy lifestyle and promote healthy behaviors such as increase in fruit and vegetable consumption and physical activity. We analyzed our data according to two guidelines for fruit and vegetable consumption: CDC and the Saudi MOH guidelines. We wanted to show that the consumption is very low regardless of what guidelines are used. We strongly believe that the guidelines in KSA should be revised to include the local diet and improve it. KSA has a food pyramid called Healthy Food Palm (Figure 1) that is based on the US Food and Drug Administration dietary guidelines for Americans. ${ }^{16}$ This food pyramid should be reviewed and changed to put greater emphasis on fruits and vegetables as opposed to consumption of grains, which is not an issue in KSA.

Moreover, we feel that educating women on the benefits of a healthy diet may lead to better uptake of fruits and vegetables at home and perhaps outside. The KSA MOH has done a remarkable job in decreasing infectious diseases, especially maternal and child health. ${ }^{29,30}$ The country employed a system to educate and inform women about healthier behaviors and disease prevention tools. ${ }^{31}$ Such a model would be very helpful to reach out to women and inform them of the benefits of fruits and vegetables and ways to prepare them to the taste of the community.

Our study provides important and timely findings. We have showed that KSA is in dire need of improving the diet of its population. Our findings call for urgent research to understand the reasons for low consumption of fruits and vegetables, focusing on price or preference in order to develop and implement culturally and countryrelevant solutions to increase the consumption of fruits and vegetables.

\section{Acknowledgments}

This study was financially supported by a grant from the $\mathrm{MOH}$ of the KSA. We would like to thank Kate Muller at the Institute for Health Metrics and Evaluation for editing the manuscript.

\section{Author contributions}

All authors have contributed to the conception and design, acquisition of data, and analysis and interpretation of data of this manuscript. All authors have drafted or revised the manuscript critically for important intellectual content. The final version of the manuscript that is to be published has been approved by all the authors where they agree to be accountable for all aspects of the work ensuring that questions related to the accuracy or integrity of any part of the work are appropriately investigated and resolved.

\section{Disclosure}

The authors would like to declare no conflict of interest.

\section{References}

1. GBD Cause Patterns; 2013. Available from: http://vizhub.healthdata. org/gbd-cause-patterns/.

2. A Glance on Agricultural Development in the Kingdom of Saudi Arabia; 2005. Available from: http://www.moa.gov.sa/files/Lm_eng.pdf.

3. WHO. Promoting a Healthy Diet for the WHO Eastern Mediterranean Region: WHO; 2014. Available from: http://www.who.int/nutrition/ publications/nutrientrequirements/healtydietguide2012_emro/en/. Accessed August 28, 2014.

4. US Department of Agriculture, US Department of Health and Human Services. Dietary Guidelines for Americans 2010; 2010. Available from: http://www.cnpp.usda.gov/sites/default/files/dietary_guidelines_for_americans/PolicyDoc.pdf. Accessed August 28, 2014.

5. Peterkin B. Dietary guidelines for Americans, 1990 edition. J Am Diet Assoc. 1990;90(12):1725-1727.

6. Bes-Rastrollo M, Martínez-González MA, Sánchez-Villegas A, de la Fuente Arrillaga C, Martínez JA. Association of fiber intake and fruit/ vegetable consumption with weight gain in a Mediterranean population. Nutrition. 2006;22(5):504-511.

7. Buijsse B, Feskens EJ, Schulze MB, et al. Fruit and vegetable intakes and subsequent changes in body weight in European populations: results from the project on diet, obesity, and genes (DiOGenes). Am J Clin Nutr. 2009;90(1):202-209.

8. Epstein LH, Gordy CC, Raynor HA, Beddome M, Kilanowski CK, Paluch R. Increasing fruit and vegetable intake and decreasing fat and sugar intake in families at risk for childhood obesity. Obes Res. 2001;9(3):171-178.

9. Joshipura KJ, Hu FB, Manson JE, et al. The effect of fruit and vegetable intake on risk for coronary heart disease. Ann Intern Med. 2001;134(12): 1106-1114.

10. Bazzano LA, He J, Ogden LG, et al. Fruit and vegetable intake and risk of cardiovascular disease in US adults: the first national health and nutrition examination survey epidemiologic follow-up study. Am J Clin Nutr. 2002;76(1):93-99.

11. Hung HC, Joshipura KJ, Jiang R, et al. Fruit and vegetable intake and risk of major chronic disease. J Natl Cancer Inst. 2004;96(21):1577-1584.

12. Liu S, Manson JE, Lee IM, et al. Fruit and vegetable intake and risk of cardiovascular disease: the women's health study. Am J Clin Nutr. 2000;72(4):922-928.

13. Dauchet L, Amouyel P, Hercberg S, Dallongeville J. Fruit and vegetable consumption and risk of coronary heart disease: a meta-analysis of cohort studies. J Nutr. 2006;136(10):2588-2593.

14. DNPAO, CDC. Nutrition for Everyone: How Many Fruits and Vegetables Do You Need?: DNPAO, CDC; 2014. Available at: http:// www.cdc.gov/nutrition/everyone/fruitsvegetables/howmany.html. Accessed August 28, 2014.

15. Amuna P, Zotor FB. Epidemiological and nutrition transition in developing countries: impact on human health and development. Proc Nutr Soc. 2008;67(1):82-90.

16. Kingdom of Saudi Arabia - Ministry of Health Portal. Dietary Guidelines for Saudis; 2013. Available at: http://www.moh.gov.sa/en/ Portal/WhatsNew/Pages/WatsNews-2013-01-14-001.aspx. Accessed August 28, 2014.

17. Kingdom of Saudi Arabia - Ministry of Health Portal. Food Pyramid; 2014. Available from: http://www.moh.gov.sa/en/. Accessed August 28, 2014. 
18. WHO. STEPwise Approach to Chronic Disease Risk Factor Surveillance. Saudi Arabia: WHO; 2005. Available from: http://www.who.int/chp/ steps/saudi_arabia/en/. Accessed August 28, 2014.

19. Craig CL, Marshall AL, Sjöström M, et al. International physical activity questionnaire: 12-country reliability and validity. Med Sci Sports Exerc. 2003;35(8):1381-1395.

20. Khan F. KSA Imports Fruits, Vegetables Worth SR4 Billion Annually; 2014. Available from: http://www.arabnews.com/node/459001. Accessed September 2, 2014.

21. Saudi Agriculture Show to Have Largest Ever Indian Participation: The Economic Times; 2014. Available form: http://economictimes. indiatimes.com//articleshow/40867833.cms. Accessed August 28, 2014.

22. Saudi Arabian Monetary Agency. Annual Report: Latest Economic Developments; 2013. Available from: http://www.sama.gov.sa/sites/ samaen/ReportsStatistics/ReportsStatisticsLib/5600_R_Annual_ En_49_Apx.pdf.

23. Food Prices in Saudi Arabia; 2014. Available from: http://www.numbeo.com/food-prices/country_result.jsp?country=Saudi+Arabia

24. USDA Foreign Agricultural Service. Saudi Arabia Food and Agricultural Import Regulations and Standards; 2011. Available from: http://gain fas.usda.gov/Recent $\% 20$ GAIN\%20Publications/Food $\% 20$ and $\% 20$ Agricultural\%20Import\%20Regulations\%20and\%20Standards\%20 -\%20Narrative_Riyadh_Saudi\%20Arabia_12-27-2011.pdf.
25. Saudi Subsidies Incur Huge Costs, Threaten Oil Exports; 2010. Available from: http://www.energy-daily.com/reports/Saudi_subsidies_incur_ huge_costs_threaten_oil_exports_999.html.

26. Powell LM, Chaloupka FJ. Food prices and obesity: evidence and policy implications for taxes and subsidies. Milbank Q. 2009;87(1): 229-257.

27. فتافيت : القناة الأولى و الوحيدة لفن الطعام في الثرق الأوسط [Fatafeet: the first and only channel in culinary art in the Middle East]; 2014. Available from: http://www.fatafeat.com/. Accessed September 15, 2014.

28. Nabhan GP. Cumin, Camels, and Caravans: A Spice Odyssey. Berkeley: University of California Press; 2014.

29. Memish ZA, Mokdad AH, AlMazroa MA, et al. Burden of disease, injuries, and risk factors in the kingdom of Saudi Arabia 1990-2010. Prev Chronic Dis. In Press 2014.

30. Aldossary A, While A, Barriball L. Health care and nursing in Saudi Arabia. Int Nurs Rev. 2008;55(1):125-128.

31. Kingdom of Saudi Arabia - Ministry of Health Portal. Women's Health; 2014. Available at: http://www.moh.gov.sa/en/HealthAwareness/ EducationalContent/wh/Pages/HealthBeforePregnancy.aspx.

32. Saudi Ministry of Health, General Directorate of Nutrition. Dietary Guidelines for Saudis. Riyadh: The Healthy Food Palm; 2012.
Nutrition and Dietary Supplements

\section{Publish your work in this journal}

Nutrition and Dietary Supplements is an international, peer-reviewed open access journal focusing on research into nutritional requirements in health and disease, impact on metabolism and the identification and optimal use of dietary strategies and supplements necessary for normal growth and development. The journal welcomes papers covering

\section{Dovepress}

original research, basic science, clinical \& epidemiological studies, reviews and evaluations, guidelines, expert opinion and commentary, case reports and extended reports. The manuscript management system is completely online and includes a very quick and fair peer-review system, which is all easy to use.

Submit your manuscript here: http://www.dovepress.com/nutrition-and-dietary-supplements-journal 